\title{
Le marché potentiel des tourteaux broyés, leurs propriétés fonctionnelles et applications
}

\author{
Aurélie Morel ${ }^{1}$, Nathalie Mantrand ${ }^{2}$, Saliha Belaid ${ }^{3}$, Michel Lopez $^{3}$, Denis Chereau ${ }^{3}$, Camille Demaille ${ }^{4}$, \\ Stéphane Pailler ${ }^{1}$, Francis Valter ${ }^{1}$, Olivier Galet ${ }^{1}$, Jacques Gueguen ${ }^{5}$, Romain Kapel ${ }^{6}$, Antonio Pizzi ${ }^{7}$ \\ et Fabrice Garrigue ${ }^{1, \star}$ \\ 1 SOFIPROTEOL, 11 rue de Monceau, 75008 Paris, France \\ 2 QUESTEL Consulting, 10 rue d'Arménie, 38000 Grenoble, France \\ 3 IMPROVE, Rue du fond Lagache, 80480 Dury, France \\ ${ }^{4}$ Rescoll, Pessac, France \\ 5 Consultant of Sofiproteol \& Improve, 44240 La Chapelle sur Erdre, France \\ ${ }^{6}$ LRGP, UMR CNRS-7274, plateforme SVS, 13 rue du bois de la Champelle, 54500 Vandoeuvre-lès-Nancy, France \\ 7 LERMAB, Nancy, France
}

Reçu le 26 octobre 2015 - Accepté le 27 mai 2016

\begin{abstract}
Résumé - La demande mondiale en produits bio-sourcés en pleine expansion engendre un intérêt croissant pour la recherche de nouvelles ressources de matières premières. Pour générer une valeur économique accrue dans les filières oléo-protéagineuses, les tourteaux, co-produits de l'extraction de l'huile, présentent des qualités pouvant être exploitées dans des secteurs diversifiés. Ces tourteaux sont principalement commercialisés en alimentation animale, mais restent peu utilisés dans le secteur de la chimie ou encore de l'alimentation humaine. Afin d'en étendre les applications, le prétraitement de la matière par broyage et classification granulométrique offre des perspectives technologiques pour la conception de nouveaux procédés d'extraction de composés d'intérêt. Le présent article a pour objectif : d'examiner la pertinence d'une diversification du marché des tourteaux, hors usage traditionnel et dans le secteur de la chimie; de caractériser la composition chimique des tourteaux ainsi que leurs propriétés techno-fonctionnelles; d'évaluer la faisabilité de valoriser ces tourteaux ainsi que leurs différentes fractions comme substituts ou additifs permettant la réduction de la teneur en produits d'origine fossile, par exemple, dans la production de formulations adhésives pour les panneaux de particules. Pour ce faire, un certain nombre d'actions ont été menées : évaluation du marché potentiel et accessible à partir des cultures métropolitaines; analyse du panorama de la propriété intellectuelle pour les marchés identifiés; caractérisation chimique des tourteaux broyés et de ses fractions solubles et insolubles; applicabilité des différentes fractions obtenues, en termes de pouvoir moussant, émulsifiant et gélifiant; premiers tests d'application à partir de tourteaux de colza et de tournesol dans le domaine des panneaux de bois composite. Les résultats obtenus ont permis : de dresser une cartographie de l'activité inventive liée à la valorisation des protéines de tourteaux de soja, colza, tournesol et farine de pois dans des applications variées en mettant en avant le dynamisme et l'intérêt croissant d'industriels et d'universitaires pour l'utilisation des protéines d'origines oléo-protéagineuses ; d'explorer les propriétés techno-fonctionnelles apportées par ces tourteaux broyés et leurs dérivés, en particulier dans les domaines des panneaux de bois composite.
\end{abstract}

Mots clés : Rapeseed / sunflower / ground plant meal / plant protein / lignocellulose

Abstract - Ground plant meal potential market, functional properties and applications. The growing demand of bio-sourced products leads to an increasing interest for the development of new resources of raw materials. In order to generate a higher economic value in the oleoproteaginous sector, meals, co-products of oil extraction present qualities capable of being exploited in a wide range of sectors. These meals are mainly commercialized in feed application, but remain relatively weak used in the chemistry domain or even in food. To enlarge these applications, the pre-treatment of the raw material by grinding and air-classification offers technological outlooks for the conception

\footnotetext{
^ Correspondance : fabrice.garrigue@evertree-technologies.com
} 
of new extraction processes of interesting components. The present publication has the following goal: to examine the diversification of oleoproteaginous meal market, out of traditional usage in the chemistry domain; to characterize the meals chemical composition and their techno-functional properties; to evaluate the feasibility of valorizing these meals and their derivatives as substitutes or additives allowing the reduction of the level in petro-chemical product, for example, for the production of adhesive formulations for particle boards. To achieve this, different actions have been performed: evaluation of the potential and accessible market starting from metropolitan crops; analysis of the panorama of intellectual property for the identified markets; chemical characterization of ground plant meals and their soluble and insoluble fractions; applicability of the different obtained fractions, in terms of foaming power, emulsifier and gelifier; first application tests starting from rapeseed and sunflower meals in the wood panel board domain. The obtained results have allowed: to draw up a map of the inventive activity bound to the valorization of proteins from rapeseed, sunflower and soy meals and pea flour in various applications, highlighting the dynamism and the growing interest for industrials and academics to use oleo-proteaginous plant proteins; to explore techno-functional properties brought by these plant meals and their derivatives, in particular in the wood panel domain.

Keywords: Rapeseed / sunflower / ground plant meal / plant protein / lignocellulose

\section{Introduction}

Globalement sur le plan international, la demande sociétale en produits agro-sourcés efficaces et ayant une empreinte environnementale favorable est en plein essor. Afin de pouvoir accompagner cette mutation, la filière oléoprotéagineuse ambitionne de mieux valoriser les composants non lipidiques issus des graines oléoprotéagineuses. Ces agro-ressources déshuilées sont en effet riches en constituants à haute valeur ajoutée, en particulier en protéines végétales. Un élément majeur du développement pour les prochaines décennies concerne l'optimisation de l'usage des ressources naturelles. Pour cela, il apparaît indispensable d'assurer le meilleur équilibre possible entre les différents usages potentiels, alimentaires et non alimentaires, de façon à asseoir une structure économique durable tout en contribuant au développement de la chimie d'origine végétale en substitution partielle de la chimie basée sur la transformation des matières fossiles.

Selon une approche économique globale, la conception d'une bioraffinerie du végétal en est la clé de voûte. Pour la construire, les applications possibles des tourteaux d'origine oléoprotéagineuse nécessitent d'être diversifiées. Le fractionnement de ces matériaux de composition hétérogène constitue une brique technologique essentielle à apporter à cet édifice. La pérennité de ces opérations technologiques est assurée par le gain de valeur associé et attendu en enrichissant le produit résultant en composé d'intérêt et/ou en lui conférant de nouvelles propriétés d'usage.

Dans la filière des oléoprotéagineux, le soja, le colza, le tournesol et le pois constituent des matières premières de choix, car riches en protéines végétales, et ont par conséquent été sélectionnées dans le cadre de ce travail. Sur le territoire métropolitain, la production de tourteaux de colza et de tournesol répond à des besoins élevés en protéines pour l'alimentation animale. Elle vise notamment la baisse de l'importation de tourteaux de soja et donc à acquérir une plus grande autonomie protéique.

Plusieurs voies de fractionnement peuvent être envisagées, dont les plus couramment utilisées sont : (1) le broyage du substrat suivi d'une classification granulométrique afin de séparer une fraction fine (faibles diamètres de particules) d'une fraction plus grossière appelée « refus » (diamètres élevés) et (2) l'extraction dans un solvant comme l'eau par exemple sui- vie d'une étape de centrifugation afin de séparer une fraction soluble d'une fraction insoluble.

SOFIPROTEOL sur financements d'origine interprofessionnelle a ainsi soutenu en 2015 le projet «PROMAT » (abréviation pour PROtéines pour MATériaux) visant à :

- valider que le domaine des matériaux représente un marché d'avenir pour les tourteaux d'oléagineux,

- évaluer la faisabilité de valoriser les tourteaux de colza et de tournesol, et ce comparativement aux performances atteintes avec les tourteaux de soja, ainsi que leurs différentes fractions comme substituts aux produits d'origine fossile entrant dans la composition de résines adhésives pour les panneaux de bois composites.

L'utilisation de ces produits enrichis en protéines et issus des oléagineux contribuerait à une réduction de l'usage de ces substances fossiles pouvant contenir des résidus toxiques ou bien produites à partir de molécules à caractère dangereux.

Ce projet vise ainsi à développer un ingrédient ou additif bio-sourcé permettant d'améliorer l'empreinte environnementale de la formulation polymérique qui le contient et ce à des coûts compétitifs. À moyen terme, des produits plus respectueux de l'environnement seront développés tout en maintenant les exigences techniques les plus élevées, en parfaite adéquation avec l'attente du marché.

Pour atteindre ces objectifs, la démarche poursuivie a été menée en deux temps. La première partie a été vouée à l'analyse de la propriété industrielle et des marchés visés pour les tourteaux afin de dresser une cartographie de l'activité inventive et du potentiel du marché. La seconde quant à elle, à travers une approche expérimentale, s'est consacrée à l'étude de la composition des tourteaux, à l'examen de l'état de dénaturation des protéines et enfin aux propriétés techno-fonctionnelles des tourteaux ou de leurs fractions. Pour orienter les formulations à élaborer dans les applications «matériaux », nous nous sommes appuyés sur les données concernant les propriétés physico-chimiques intrinsèques des fractions solubles issues des tourteaux.

Sur la base de ces connaissances fondamentales, des systèmes complexes ont été formulés et leurs performances applicatives dans le domaine des matériaux évaluées afin de valider les marchés potentiels. 


\section{Matériel et méthodes}

\subsection{Matériel}

\subsubsection{Les tourteaux}

Les tourteaux de colza et de tournesol ont été fournis par Saipol (respectivement les sites de Grand Couronne et Bassens, France). Ces tourteaux ont été obtenus par une étape de pression à chaud, suivie d'une étape d'extraction par solvant organique (i.e. l'hexane) des écailles de pression (qui désignent le produit obtenu à l'issu de l'étape de pression à chaud) pour extraire l'huile végétale.

Par étape de pression à chaud, on entend une étape comportant un préchauffage des graines de colza jusqu'à $90^{\circ} \mathrm{C}$, puis un broyage desdites graines et un pressage dans une vis sans fin où la température peut atteindre jusqu'à $120^{\circ} \mathrm{C}$. On obtient alors un tourteau gras comportant $12 \%$ à $14 \%$ d'huile résiduelle.

Enfin, l'étape d'extraction par solvant organique est suivie d'une étape de désolvantisation.

Les tourteaux ainsi obtenus contiennent 1 à $2 \%$ d'huile résiduelle pour 10 à $12 \%$ d'humidité.

Le tourteau de soja a été quant à lui fourni par Cargill.

\subsubsection{Les résines pétrochimiques}

Deux types de résines ont été testés : pMDI (polyméthylène diphényl 4,4'-diisocyanate, BAYER, pureté de $99 \%$ ) et UF (Urée-Formol, DYNEA, extrait sec de $65 \%$ ).

\subsubsection{L'eau}

L'eau est une eau déminéralisée.

\subsubsection{L'urée}

L'urée est l'urée U5378 de chez Sigma Aldrich, USA.

\subsubsection{Les particules de bois}

Les particules (dans le cas présent, des copeaux) de bois fins proviennent de Kronofrance.

\subsection{Méthodes}

\subsubsection{Cartographie de l'activité inventive}

Le travail de veille a été mené en partenariat avec Avenium ${ }^{1}$.

- Périmètre de recherche

La recherche a été réalisée sous le portail ORBIT (Questel) de 1994 à 2014. Aucune restriction géographique n'a été effectuée.

- Segmentation et mots clés

Les équations de recherches ont été rédigées afin d'identifier les technologies traitant des protéines issues des tourteaux de graines d'oléoprotéagineux et notamment de soja, colza, tournesol et pois (i.e. seules ces quatre espèces ont

\footnotetext{
${ }^{1}$ Société de conseil en management et stratégie de propriété industrielle.
}

été cherchées dans les revendications). Une équation de recherche, intégrant mots-clés et classes CIB (Classification Internationale des Brevets) si nécessaire pour assurer des données d'interprétation pertinente, a ainsi été réalisée.

Voici l'équation finale qui a été utilisée pour constituer la base de l'étude. De nombreuses combinaisons ont bien sûr été testées au préalable.

La première partie $(\mathrm{P} 1)$ concerne les matières premières : les tourteaux d'oléoprotéagineux d'intérêts ainsi que des termes plus génériques, la deuxième partie $(\mathrm{P} 2)$ concerne les protéines et dérivés et enfin la troisième partie (P3) concerne l'extraction. P1 et P2 ont été cherchés dans la même phrase et P3 devait apparaître dans les mêmes champs.

P1 = $\left(\left(\left(\left(C A T T L E \_C A K E\right.\right.\right.\right.$ OR OIL_CAKE OR PRESS_CAKE OR PELLET+ OR ((PLANT OR VEGETABLE OR CROP+ OR RENEWABLE OR AGRICULTUR+) 2D (RESIDUE+ OR BIOMASS)) OR GROUND PLANT MEAL OR PROTEIN CROP? OR OIL_SEED? OR OLEAGINOUS OR PROTEAGINOUS OR RAPE_SEED? OR CANOLA ? OR BRASSICA NAPUS OR SUN_FLOWER? OR HELIANTHUS ANNUUS OR SOY OR SOYA OR SOJA OR SOY_BEAN? OR GLYCINE MAX OR GLYCINE SOJA OR PEA OR PEAS OR PISUM OR CHICK_PEA? OR CICER ARIETINUM OR PIGEON PEA ? OR CAJANUS CAJAN)

P2 = (PROTEIN ? OR POLY_PEPTIDE ? OR PEPTIDE? OR AMINO_ACID ?))

$\mathrm{P} 3=($ EXTRACT + OR TRANSFORM+ OR RECYCL+ OR VALORISATION OR VALORIZATION OR REUS+ OR VALUTATION OR ISOLAT+ OR FRACTIONAT+ OR CONCENTRAT+ OR ISOLAT+))

BI/CLMS/ICLM AND PRD >= 1994) NOT (A01H OR C12N-015 OR A61K-048 OR C12N-001 OR C12N-005 OR C40B)/IPC/CPC

Cette requête a permis d'identifier près de 8000 brevets qui ont ensuite été revus pour enlever les moins pertinents. Et la base a été segmentée par : application, type de matière première, type d'extraction.

\subsubsection{Broyage du tourteau et extraction dans l'eau}

Pour plus de clarté, les différents produits, décrits dans la suite de la publication et obtenus successivement par extraction d'huile, puis broyage et enfin fractionnement dans l'eau, sont schématisés (Fig. 1).

\section{- Broyage du tourteau}

Le broyage en vue de l'obtention d'une distribution granulométrique contrôlée est essentiel pour un contrôle efficient des phénomènes d'extraction des bio-polymères solubles en milieu aqueux. Cette opération de broyage a été réalisée chez Poittemill sous le contrôle d'IMPROVE.

Nous avons été attentifs à limiter l'échauffement du produit afin de ne pas dépasser $60^{\circ} \mathrm{C}$ dans l'air de sortie du filtre. L'air passant au travers du broyeur est aspiré dans la halle pilote qui était à $20^{\circ} \mathrm{C}$ pendant toute la durée des essais.

L'air passant au travers du broyeur était aspiré de la halle d'essai dont la température était de $20{ }^{\circ} \mathrm{C}$ pendant toute la 


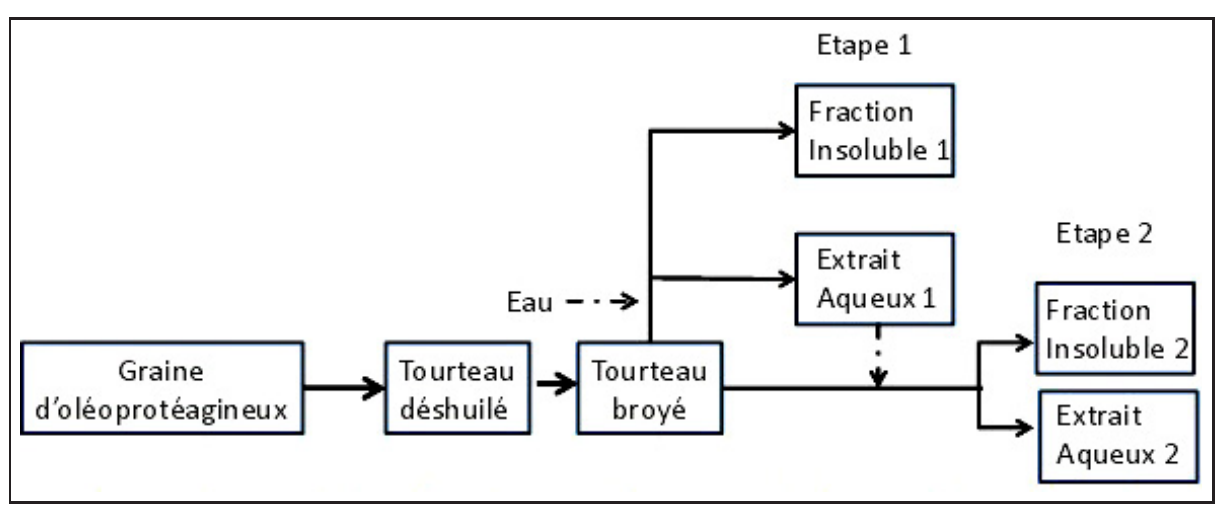

Fig. 1. Produits obtenus selon un enchaînement des différentes étapes de procédé envisagées, de la graine d'oléoprotéagineux aux différentes fractions solubles (i.e. extraits aqueux) et insolubles dans l'eau. De gauche à droite : le tourteau déshuilé obtenu par trituration de la graine oléaprotéagineuse ; le tourteau broyé produit par broyage et classification granulométrique successivement et les fractions insolubles 1 et 2 et extraits aqueux 1 et 2 obtenus par une mise en suspension du tourteau broyé dans l'eau suivie d'une centrifugation.

durée du broyage. L'installation a été nettoyée entre chaque broyage.

Les tourteaux ont été broyés à l'aide d'un broyeur ATTRIMILL (Poittemill) d'une puissance de $11 \mathrm{~kW}$ permettant l'obtention de débits entre 10 et $300 \mathrm{~kg} / \mathrm{h}$ en particules fines. Le débit obtenu avec le broyeur est le résultat d'une régulation activant la vis d'alimentation du broyeur en fonction de l'intensité consommée. La vis est en fonctionnement jusqu'à ce que la consommation électrique du broyeur dépasse la limite de 19 Ampère (A). Une fois cette limite dépassée, la vis s'arrête automatiquement, et redémarre dès que l'ampérage passe sous la limite de $18 \mathrm{~A}$. Ce système de «ping pong » dure tant qu'il y a du produit dans la trémie d'alimentation du broyeur. Ce broyeur est muni d'un cyclone dynamique permettant d'effectuer une classification granulométrique et une sélection des particules en fonction de leur taille.

En pratique, les réglages effectués sont les suivants :

- vitesse broyeur de 4880 tours/min,

- cyclone dynamique à $10 \mathrm{~Hz}$.

Le rendement de cette opération (broyage et cyclone) est supérieur à $99 \%$.

Les tourteaux obtenus présentent alors le profil de distribution granulométrique suivant :

- $D_{50}$ (diamètre médian volumique) $<40 \mu \mathrm{m}$

- $D_{99}<140 \mu \mathrm{m}$.

\section{- Procédé d'extraction aqueuse}

Les conditions opératoires de l'extraction aqueuse, réalisées chez IMPROVE, sont les suivantes :

- Étape 1 : concentration massique du tourteau dans l'eau $25 \%(\mathrm{p} / \mathrm{p})$; température ambiante; agitation au barreau aimanté : 500 tours/min pendant $2 \mathrm{~h}$; volume de $400 \mathrm{ml}$ à la première étape puis de $200 \mathrm{ml}$ en seconde étape, centrifugation pendant $10 \mathrm{~min}$ : les suspensions réparties en 200 et $100 \mathrm{ml}$ pour les étapes 1 et 2 respectivement.

- Étape 2 : Le surnageant de l'étape 1 est utilisé comme solvant d'extraction à la place de l'eau dans les mêmes conditions que précédemment.

\subsubsection{Première caractérisation chimique des tourteaux}

Les opérations décrites ci-après ont été conduites chez IMPROVE.

\section{- Granulométrie des poudres}

La distribution de taille des particules des poudres broyées chez Poittemill a été caractérisée par un granulomètre laser de Modèle HELOS type WINDOX 5. La gamme de mesure est de 0,5 à $875 \mu \mathrm{m}$. Les caractéristiques sont les suivantes :

- vitesse d'alimentation de $50 \%$,

- cycle de mesure de $100 \mathrm{~ms}$,

- pression de 1 bar.

Le diamètre médian (noté D50) est mesuré pour chaque tourteau broyé.

\section{- Teneur en protéines}

Le taux de protéines des tourteaux a été mesuré par dosage de l'azote total selon la méthode Dumas (facteur de conversion Azote/protéines pour les deux sources (colza et soja) pris égal à 5,7). Cette technique consiste à provoquer la combustion « éclair» de l'échantillon à $960^{\circ} \mathrm{C}$. Les gaz produits sont conduits par un gaz vecteur, le $\mathrm{CO}_{2}$.

Des pièges et des catalyseurs d'oxydation et de réduction, présents dans le système, permettent de ne conserver que le gaz qui nous intéresse $\left(\mathrm{N}_{2}\right)$. Ce gaz est séché et conduit vers un détecteur catharométrique. Le résultat obtenu est sous format de pourcentage d'azote, transformé en pourcentage de protéines par multiplication par un facteur de conversion. Granulométrie des poudres.

Pour la suite des méthodes décrites, toutes les mesures ont été effectuées dans les 24 à 48 h qui suivirent la préparation des échantillons (i.e. temps d'incubation).

\section{- Identification des protéines par électrophorèses dénatu- rantes sur gel d'acrylamide (SDS-PAGE)}

Les électrophorèses en conditions dénaturantes (en milieu SDS) ont été réalisées en utilisant des gels d' acrylamide à $12 \%$ 
pré-coulés de chez BioRad fournis avec le kit contenant (le tampon échantillon, le tampon de migration).

Les échantillons sont préparés dans du tampon d'échantillon selon la méthode de Laemmli (277 mM Tris-HCl, $\mathrm{pH}$ 6,8). La réduction a été réalisée en présence de $\beta$-mercaptoéthanol et en chauffant à $100{ }^{\circ} \mathrm{C}$ pendant $1 \mathrm{~min}$. La migration est conduite dans le tampon tris/glycine/SDS à un pH de 8,3 et un voltage de 180 volts pendant environ $45 \mathrm{~min}$.

Le standard de masse moléculaire utilisé pour l'identification des protéines est un standard BioRad conditionné enTris Tricine à 10-20\% avec des tailles en kDa allant de 2 à 250.

La coloration a été réalisée en trois étapes successives : fixation pendant $1 \mathrm{~h}$ dans la solution Coomassie Destaining Brilliant Blue R-250, coloration avec cette même solution pendant environ $1 \mathrm{~h}$, suivie enfin d'une décoloration avec une solution Coomassie destaining Brilliant Blue R-250 pendant environ $4 \mathrm{~h}$.

\section{$-\mu-D S C$}

Les propriétés thermodynamiques des différentes fractions ont été mesurées par microcalorimétrie différentielle à balayage ( $\mu$-DSC). Cette technique est basée sur l'application d'une cinétique de chauffage des échantillons, l'énergie mise en jeu est mesurée par le système en faisant un différentiel avec un témoin (solvant). La cinétique de température appliquée est de $0,3{ }^{\circ} \mathrm{C} / \mathrm{min}$.

L'appareillage utilisé est une $\mu$-DSC de chez SETARAM ( $\mu \mathrm{SC})$. Les échantillons issus du fractionnement dans l'eau ont été analysés sans ajustement du pH. Les quantités d'échantillons introduites dans les capsules allant dans l'appareil sont de $400 \mathrm{mg}$.

Les échantillons analysés en DSC sont : les poudres de tourteaux, les fractions solubles (surnageant avec 23 et $34 \%$ de protéines/MS pour colza et soja respectivement) extraites précédemment et les fractions insolubles (culot avec 31 et $46 \%$ de protéines/MS pour colza et soja respectivement).

\subsubsection{Propriétés fonctionnelles}

\section{- Propriété interfaciale eau/air et moussage}

La tension superficielle a été mesurée au moyen d'un tensiomètre Krüss selon la méthode de Wilhelmy (lame). Les protéines de colza et soja obtenues par extraction dans l'eau sont dispersées à une concentration de $1 \mathrm{mg} / \mathrm{ml}$ de protéines dans l'eau milliQ. Le volume de ces solutions introduites dans la cuve de mesure est de $60 \mathrm{ml}$, concentration comparable à celle utilisée pour l'étude des mousses. La tension superficielle obtenue est exprimée en $\mathrm{N} / \mathrm{m}$. Cette valeur nous permet de constater la réduction de la tension superficielle par les protéines comparativement à celle de l'eau $\left(72 \mathrm{mN} / \mathrm{m}\right.$ à $\left.20{ }^{\circ} \mathrm{C}\right)$ prise comme référence.

Les propriétés moussantes ont été appréciées à l'aide d'un foamscan (TECLIS, méthode développée par l'INRA de Nantes et transférée chez IMPROVE) qui permet de former une mousse par bullage et d'enregistrer ainsi le volume de mousse formée ainsi que sa stabilité dans le temps. Dans cette étude, nous avons travaillé à un débit d'air de $200 \mathrm{ml} / \mathrm{min}$ pendant $30 \mathrm{~s}$. La stabilité de la mousse est suivie pendant $600 \mathrm{~s}$.

\section{- Propriété interfaciale et émulsification huile/eau}

La mesure de la tension interfaciale eau/huile a été réalisée à l'aide d'un tensiomètre Krüss selon la méthode de Denoüy (anneau). Les protéines de colza et soja obtenues par extraction dans l'eau sont dispersées à une concentration de $10 \mathrm{mg} / \mathrm{ml}$, concentration comparable à celle utilisée pour l'étude des émulsions. La tension interfaciale obtenue est exprimée en $\mathrm{N} / \mathrm{m}$. Cette valeur nous permet de constater la réduction de la tension interfaciale par les protéines comparativement à celle de référence obtenue à l'interface eau/huile qui est de l'ordre de $20 \mathrm{mN} / \mathrm{m}$ à $20^{\circ} \mathrm{C}$.

Les émulsions étudiées sont des émulsions huile dans eau à une proportion de $25 / 75$ en poids. La solution protéique dans l'eau milliQ est préparée à $10 \mathrm{mg} / \mathrm{ml}$ de protéines. Un premix est effectué à l'aide d'un ultra-turrax pendant $1 \mathrm{~min}$ à 5000 tours/min. L'émulsion proprement dite est obtenue par passage sur bain à ultra-sons pendant $1 \mathrm{~min}$ avec des interruptions toutes les $10 \mathrm{~s}$ pour ne pas chauffer l'émulsion. La mesure de la taille des particules obtenues est faite au granulomètre laser Malvern (Mastersizer 3000). Les mesures sont réalisées dans l'eau et dans le SDS (dodécyl sulfate de sodium, Fisher) à J0 Le SDS est utilisé pour, éventuellement, défloculer l'émulsion.

\section{- Caractéristiques rhéologiques et gélification}

Les propriétés rhéologiques des différentes fractions ont été caractérisées à l'aide d'un rhéomètre DHR 2 (TA Instruments) à vitesse de rotation imposée.

Les conditions physico-chimiques ( $\mathrm{pH}$ et force ionique) n'ont pas été ajustées. Les fractions solubles et insolubles sont remises dans l'eau milliQ pour avoir des solutions à des concentrations de 5,10 et $15 \% \mathrm{p} / \mathrm{p}$ de protéines.

D'une part, les propriétés épaississantes ont été étudiées par mesure de la viscosité en fonction du cisaillement. Les mesures ont été effectuées avec une géométrie Cône-plan $\left(2^{\circ}\right)$, entrefer de $1200 \mu \mathrm{m}$, vitesse de cisaillement de 0,01 à $100 \mathrm{~s}^{-1}$ puis de 100 à $0,01 \mathrm{~s}^{-1}$.

D'autre-part, les propriétés gélifiantes des fractions protéiques ont été caractérisées par une géométrie plan-plan, entrefer $1200 \mu \mathrm{m}$ avec un pourcentage de déformation défini par un balayage en fréquence préalable qui détermine la région d'équilibre du système. La gélification est obtenue en appliquant une rampe de température de 5 à $95{ }^{\circ} \mathrm{C}$ à raison de $3{ }^{\circ} \mathrm{C} / \mathrm{min}$, un repos à $95^{\circ} \mathrm{C}$ pendant 15 min suivie d'un refroidissement de 95 à $5^{\circ} \mathrm{C}$. Les modules $\mathrm{G}^{\prime}$ (module conservatif) et $\mathrm{G}^{\prime \prime}$ (module dissipatif) sont enregistrés tout au long de la mesure. Cette technique permet de déterminer une température de gélification qui correspond à la température à laquelle apparaît un module $G^{\prime}$ et la force du gel qui correspond au module G' maximal obtenu en fin de gélification.

\subsubsection{Production de panneau de bois}

Des panneaux de particules agglomérés ont été préparés à l'échelle laboratoire chez Rescoll. Pour des raisons de dimensionnement les panneaux ont été préparés en une couche, à base de copeaux fins (correspondant à la couche intérieure d'un panneau classique). 


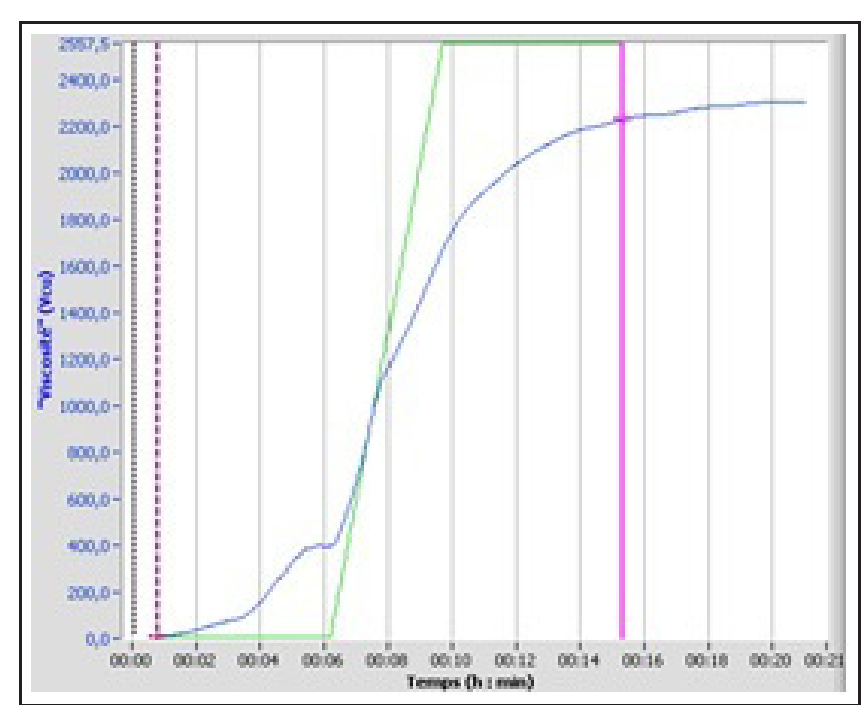

Fig. 2. Exemple de mesure d'un temps de gel d'une formulation adhésive au trombomat (Viscosité exprimée en Vcu (Viscous Coupling Unit)).

- Formulation de l'adhésif : le mélange a été effectué mécaniquement à l'aide d'une hélice à quatre pâles à une vitesse variable de 800 à 1000 tours/min durant 5 min. Pour cela, le tourteau broyé a été ajouté à l'eau, à une concentration de $25 \%$ en poids de matière sèche de tourteau broyé par rapport au poids total d'eau et de tourteau $(\mathrm{p} / \mathrm{p})$. De l'urée peut éventuellement être solubilisée dans l'eau avant ajout du tourteau broyé sous agitation mécanique (environ 400 tours/min). La suspension de tourteau obtenue est ensuite mélangée à la résine pétro-sourcée (pMDI ou UF). La teneur en extrait sec de la composition adhésive est enfin ajustée de tel sorte que la viscosité de la formulation adhésive reste constante par rapport à celle mesurée sur une formulation adhésive sans tourteau.

- Caractérisation du mélange collant :

- mesure de l'extrait sec à l'aide d'une balance halogénée $\left(105^{\circ} \mathrm{C}\right.$, temps de stabilisation de $\left.20 \mathrm{~s}\right)$,

- mesure d'un temps d'écoulement à l'aide de la coupe de viscosité Lory Elcometer 2215 (essai non normalisé),

- mesure du temps de gel par suivi de l'évolution de la viscosité au Trombomat (température d'essai 180 à $200^{\circ} \mathrm{C}$, cette gamme de températures correspondant à celles mises en œuvre lors du passage à chaud d'un panneau de bois composite). Un exemple de courbe viscosité en fonction du temps est donné Figure 2.

- Préparation du panneau de bois composite :

- etuvage des particules pendant $12 \mathrm{~h}$ à $60{ }^{\circ} \mathrm{C}(3 \%$ d'humidité résiduelle des particules à la fin de ce traitement contrôlé à la balance à extrait-sec),

- mélange manuel des particules après refroidissement suite à la sortie de l'étuve $\left(T=30-35^{\circ} \mathrm{C}\right)$ avec le mélange collant pendant $2 \mathrm{~min}$, puis ajout de la cire et mélange manuel pendant $1 \mathrm{~min}$,

- incorporation du mélange dans un moule dont les dimensions ont été calculées afin de permettre de fixer la densité du panneau à $650 \mathrm{~kg} / \mathrm{m}^{3}$ (i.e. les panneaux mesurent environ $250 \times 350 \mathrm{~mm}^{2}$ pour une épaisseur finale de $7-8 \mathrm{~mm}$ ),

- température de presse (Presse MI41 de chez TechniHispania) à $200^{\circ} \mathrm{C}$ pendant $4 \mathrm{~min}$.

- Caractérisation des propriétés des panneaux de bois :

- gonflement à l' eau : mesure de gonflement en épaisseur du panneau de bois après immersion totale dans l'eau (NF EN 317, eau à température ambiante, mesure de l'épaisseur à $t 0, t+2 \mathrm{~h}, t+24 \mathrm{~h}$, moyenne sur 3 éprouvettes),

- résistance mécanique : essai de flexion 3 points, évaluation de la contrainte maximale, et du module (Inspiré de la norme NF EN 310, machine $400 \mathrm{M}$, capteur $2 \mathrm{kN}$, vitesse d'essai $2 \mathrm{~mm} / \mathrm{min}$, moyenne sur 5 éprouvettes).

\section{Résultats}

\subsection{Cartographie de l'activité inventive et du potentiel du marché des adhésifs et des polyuréthanes}

\subsubsection{La dynamique inventive et la couverture géographique des brevets}

La cartographie révèle l'existence de plus de 7000 familles de brevet (i.e. une famille de brevets regroupe tous les brevets nationaux (US, FR, ...) d'une invention) au niveau mondial dont $69 \%$ sont encore en vigueur.

L'activité inventive montre un dynamisme particulier depuis le début des années 2000 (Fig. 3). L'augmentation du nombre de dépôts est uniquement due aux nouveaux dépôts en Asie : les dépôts en Europe restent stables, tandis qu'ils diminuent en Amérique du Nord. C'est un domaine dans lequel les acteurs académiques sont peu présents à l'exception des Chinois.

Seulement environ un quart des demandes passent par la voie PCT et plus de $40 \%$ des dépôts prioritaires de brevets, concernant essentiellement l'extraction et la valorisation des protéines végétales, sont conduits en Chine selon une stratégie d'extension géographique limitée au mieux à l'Asie voire à la Chine uniquement (i.e. $91 \%$ des familles de brevet déposées prioritairement sur le territoire asiatique ne sont pas étendues).

\subsubsection{Les matières premières}

Le soja est très largement dominant par rapport au colza, tournesol et pois. $83,6 \%$ des brevets revendiquent uniquement le soja.

Pour le soja, les dépôts prioritaires se font majoritairement en Asie, tandis que pour le colza ils sont principalement localisés aux Etats-Unis. L'Europe est quant à elle plus fortement positionnée sur le pois. Enfin, les dépôts prioritaires russes concernent surtout le Tournesol.

\subsubsection{Les acteurs et les procédés d'extraction}

En termes de déposants, le panorama est assez fragmenté : les dix premiers déposants en terme de nombre de brevets représentent à peine $10 \%$ des dépôts. Comme représenté sur 


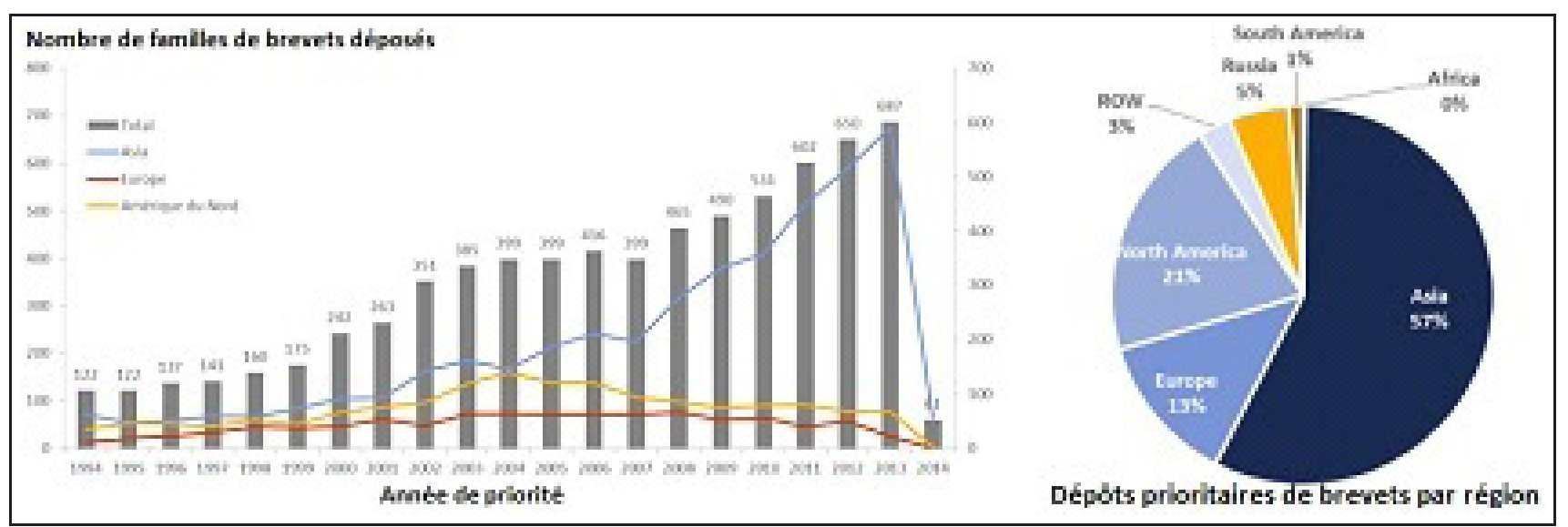

Fig. 3. Évolution temporelle du nombre de brevets sur la thématique de 1994 à aujourd'hui et localisation géographique des déposants (Compte tenu du délai existant entre la date de dépôt d'une demande et sa publication (18 mois), les brevets déposés en 2012 et 2013 n'apparaissent pas tous sur le graphique présenté à gauche).

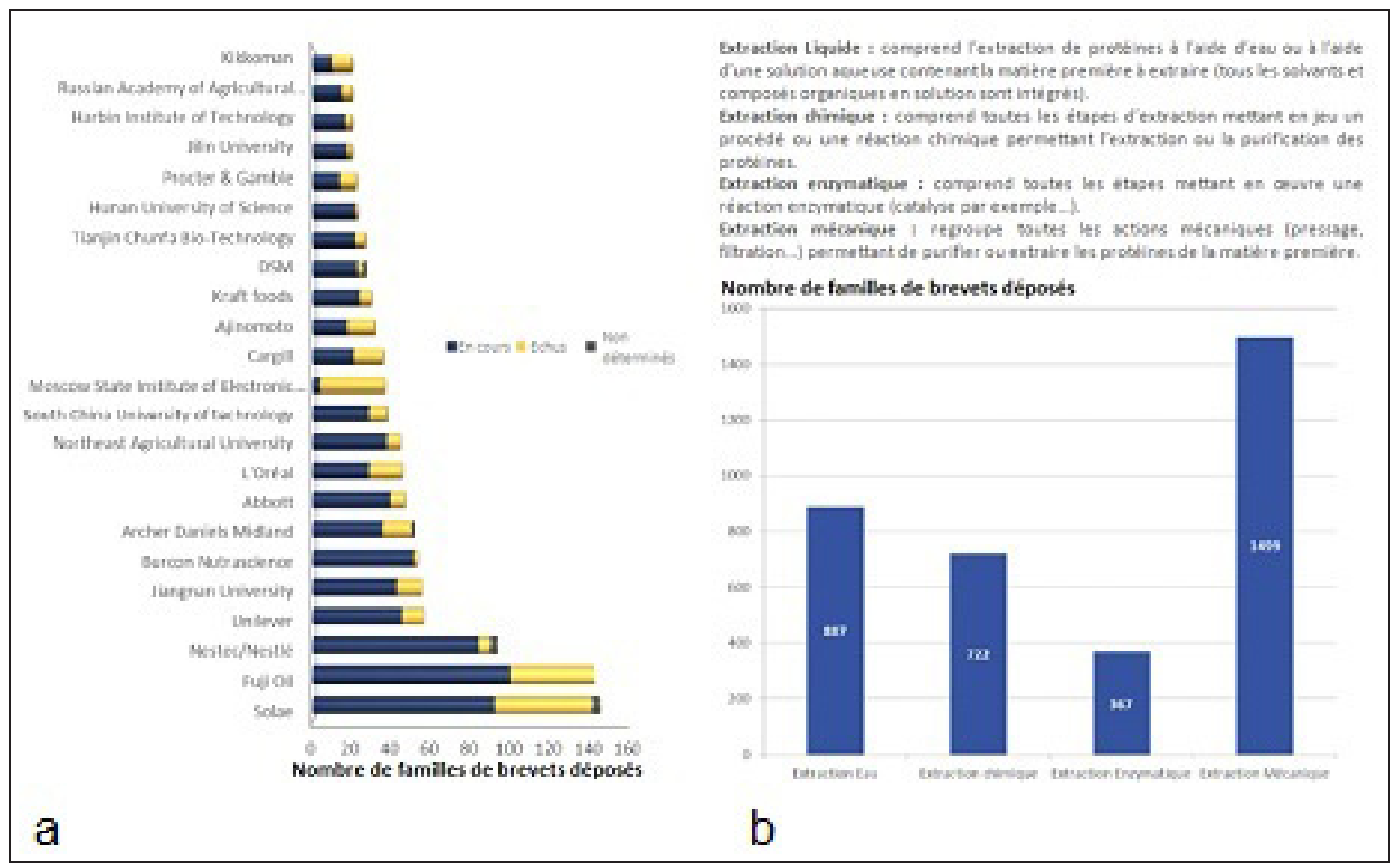

Fig. 4. (a) Principaux déposants et (b) segmentation des brevets par type d'extraction.

la Figure 4a, les seuls académiques présents parmi les premiers déposants sont chinois.

Quant aux types de procédés d'extraction des protéines, ils se répartissent comme indiqué sur la Figure 4b.

Les acteurs majeurs, Solae et Fuji Oil, sont bien placés dans tous les procédés d'extraction, suivis de près par Burcon Nutrascience. Les brevets de cette société canadienne sont tous assez récents et très bien étendus ( 6,6 pays en moyenne par famille). Par ailleurs, la plupart des brevets du domaine revendiquent au moins deux modes d'extraction ce qui montre bien que l'extraction repose en général sur une combinaison d'étapes et donc de procédés différents.

\subsubsection{Les domaines applicatifs}

En ce qui concerne les domaines applicatifs, l'alimentation humaine et animale et le secteur santé à eux seuls représentent $82 \%$ des brevets, comme indiqué sur la Figure 5.

Les acteurs chinois sont fortement positionnés sur l'alimentation en général et sur les adhésifs et les liants pour le bois, ces dernières applications étant majoritairement 


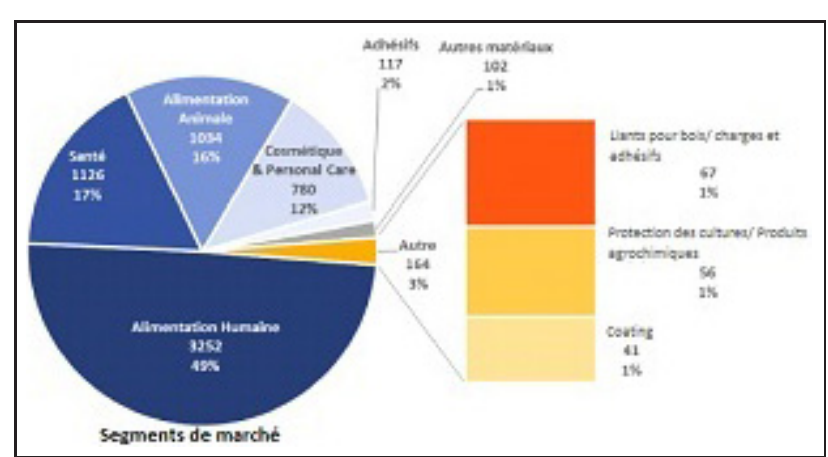

Fig. 5. Segmentation des brevets sur la thématique depuis vingt ans par marché applicatif.

dominées par des solutions à base de protéines de soja. En revanche, les acteurs européens apparaissent plus fortement sur le marché de la cosmétique.

\subsubsection{Le marché des adhésifs pour le bois et des polyuréthanes}

Parmi les domaines explorés, le secteur d'activité des adhésifs, des liants pour le bois et des mousses polyuréthane semble prometteur. Plus précisément, les applications pour la production de panneaux de bois composites et de produits d'emballage comme les mousses polyuréthanes ont fait l'objet d'une étude de marché approfondie.

\section{- Les panneaux de bois composite}

Avant la deuxième guerre mondiale, les adhésifs naturels, comme en particulier les produits adhésifs à base de protéines tels que le sang ou le caséinate, étaient fortement utilisés dans l'industrie du traitement de surface. L'utilisation de ces adhésifs bio-sourcés a ensuite laissé place à des résines pétrochimiques (urée/formaldéhyde, phenol/formaldéhyde, pMDI, ... ) souvent plus performantes mais présentant un caractère non renouvelable et une toxicité (e.g. le formaldéhyde).

Le marché des résines adhésives pour panneaux de bois composite serait de plus de 5 millions de tonnes en Europe et en Amérique du Nord, avec une croissance de plus de $5 \%$ par an (Transparence Market Research, 2013 ; United Soybean Board, Omnitech. 2007). Ces résines sont à $99 \%$ d'origine fossile. Leur performance et leur facilité d'utilisation dans les procédés industriels de fabrication des panneaux de bois composite ont permis un développement de panneaux performants expliquant une grande partie de la croissance de l'utilisation de ce type de matériaux dans la construction et dans l'ameublement dont Ikea est la figure emblématique (i.e. $30 \%$ des panneaux de bois composite fabriqués en Europe sont utilisés par Ikea).

Depuis le début des années 2000, les acteurs de cette industrie que cela soit au niveau des fabricants de résines adhésives ou en aval au niveau des fabricants de panneaux de bois font face à des nouveaux enjeux notamment (a) des enjeux environnementaux avec une pression réglementaire accrue pour réduire les émissions de composés organiques volatiles et de formaldéhyde (Marutsky, 1989) à la fois lors la fabrication de panneaux mais aussi au niveau des produits finis, et (b) une pression sur les prix assez significative.

Par conséquent, le caractère non-renouvelable de ces molécules et en particulier la toxicité du formaldéhyde a conduit à relancer l'intérêt pour les adhésifs protéiques. Les propriétés adhésives de nombreuses protéines végétales ont ainsi été évaluées dans le domaine particulier des panneaux de bois. Les principales sources de protéines citées (liste non exhaustive) sont les farines ou encore les isolats de protéines de soja (essentiellement), le gluten de blé, les isolats de protéines de maïs (zéines), et de pois (plus marginalement) et enfin de colza et de coton (marginalement) (voir par exemple les références académiques (Amaral-Labat et al., 2008; Cheng et al., 2013; He et al., 2014; Hettiarachchy et al., 1995 ; Khosravi et al., 2010 ; Lei et al., 2010 ; Nordqvist et al., 2010; Sun et al., 2005; Wang et al., 2002; Zhong et al., 2003); mais aussi les brevets : WO01/59026 (Heartland); US2005/0070635 (Georgia Pacific); US2006/0231968 (Georgia Pacific); EP 1742542 (Hercules); WO2010102297 (BioPolymer Technologies); WO2010102284 (BioPolymer Technologies); WO2011156380 (BioPolymer Technologies); WO201336739 (BioPolymer Technologies).

De façon générale, les inconvénients recensés selon la littérature pour l'utilisation des matériaux protéiques en remplacement des résines pétro-sourcées sont les suivants : (i) un faible temps de stockage des isolats de protéines; (ii) une faiblesse relative de la propriété d'adhésion, et enfin (iii) une résistance à l'eau très faible. Ces deux derniers points sont bien évidemment des verrous qui ont nécessité des études complémentaires pour être en partie levés. Le développement des nouveaux produits qui découle de l'ensemble de ces travaux identifiés dans l'état de l'art fait l'objet d'une étude préliminaire présentée dans le paragraphe qui suit.

\section{- Les mousses polyuréthanes}

Ces problématiques sont équivalentes dans le domaine des polyuréthanes. Leur maturité y est toutefois plus grande dans l'utilisation de produits bio-sourcés. La recherche de systèmes moins coûteux avec une réduction de l'utilisation des isocyanates, famille de produits toxiques représentant la matière première principale des polyuréthanes, est très active. Le marché des mousses polyuréthanes rigides ou flexibles représente environ 4 à 5 Millions de tonnes d'isocyanates en Europe et Amérique du Nord avec une croissance du marché de 3 à $5 \%$ par an (Icis, SRI-CEH. 2009-2012).

Plus précisément, depuis plus de vingt ans, l'utilisation de ressources naturelles dans ce domaine enregistre ainsi un intérêt croissant. L'amidon (principalement de maïs) et ses dérivés a tout d'abord été abondamment utilisé, puis progressivement supplanté par des matériaux plus riches en protéines comme la caséine et le soja (voir en particulier les références académiques (Cunningham et al., 1992; Lin et al., 1997; Li et al., 2012)). Les caractéristiques physiques des mousses ainsi obtenues sont modifiées par l'introduction de ces matières premières bio-sourcées et souvent remarquables. Par conséquent, elles nécessitent le développement de nouvelles formulations pour remplacer les solutions existantes. 
Tableau 1. Composition chimique des tourteaux et leurs fractions solubles et insolubles et taille de particules des tourteaux broyés.

\begin{tabular}{|c|c|c|c|c|c|}
\hline \multirow{3}{*}{\multicolumn{2}{|c|}{$\begin{array}{l}\text { Produ it } \\
\text { Tourteau déshuilé }\end{array}$}} & Nature & Extrait sec (\%) & Taux de protéines & D50 \\
\hline & & colza & 88,6 & 34 & \\
\hline & & soja & 88,9 & 53 & 1 \\
\hline \multirow{4}{*}{$\begin{array}{l}\text { Turbo- } \\
\text { séparation du } \\
\text { tourteau }\end{array}$} & Fines & colza & 95,5 & 33 & 25 \\
\hline & & soja & 91,9 & 1 & 33 \\
\hline & Refus & colza & 97,9 & 35 & $>120$ \\
\hline & & soja & 91,6 & 1 & $>120$ \\
\hline \multirow{4}{*}{$\begin{array}{l}\text { Fractionnement } \\
\text { de fines dans } \\
\text { l'eau après } \\
\text { l'étape } 1\end{array}$} & Solubles & Colza & 5,2 & 18 & 1 \\
\hline & Insolubles & & 31,4 & 41 & 25 \\
\hline & Solubles & Soja & 8,1 & 29 & l \\
\hline & Insolubles & & 28,5 & 60 & 53 \\
\hline \multirow{4}{*}{$\begin{array}{l}\text { Fractionnement } \\
\text { des fines dans } \\
\text { Peau après } \\
\text { P'étape } 2\end{array}$} & Solubles & Colza & 10,8 & 21 & 1 \\
\hline & Insolubles & & 30,3 & 38 & 34 \\
\hline & Solubles & Soja & 16,1 & 34 & l \\
\hline & Insolubles & & 29,8 & 51 & 48 \\
\hline
\end{tabular}

\section{- L'impact estimé sur les bio-ressources}

Les secteurs des panneaux de bois composite et des mousses polyuréthane sont donc très demandeurs de systèmes bio-sourcés complets ou d'additifs d'origine bio-sourcée permettant la réduction de l'utilisation des produits d'origine fossile. La contrainte reste toutefois forte en terme de processus de qualification technique avec un coût complet des produits finis à minima équivalent voir inférieur, mais aussi des temps d'homologation longs pouvant aller jusqu'à deux années. De telles durées sont requises si la mise en œuvre des nouvelles solutions suppose des changements de procédés dans des usines de fabrication fonctionnant la plupart du temps en procédés continus.

Dans ces conditions, le marché potentiel pour des dérivés de tourteaux d'oléo-protéagineux apportant ces performances est estimé en Europe et Amérique du Nord à environ 500 à $700 \mathrm{kt}$ pour les résines adhésives dans les panneaux de bois composite et à environ 10 à 20 kt d'additifs pour le marché des mousses polyuréthanes.

\subsection{Potentiels techno-fonctionnels des tourteaux}

\subsubsection{Composition et état de dénaturation des protéines}

La composition des tourteaux et de leurs fractions est présentée dans le Tableau 1.

Comme attendu, le taux de protéines mesuré pour le tourteau de colza représente environ un tiers de la matière, tandis que celui pour le tourteau de soja environ la moitié.

Par ailleurs, ces résultats montrent que la seconde étape de fractionnement des fines dans l'eau permet de concentrer en matière sèche les fractions solubles, et dans une moindre mesure, à les enrichir en protéines.

Ces différences de volumes d'extraction et mode d'agitation expliquent les différences constatées en matière sèche et en concentrations protéiques.

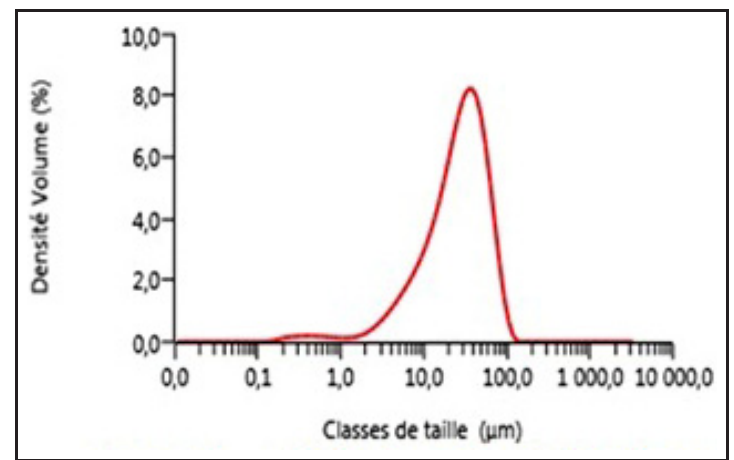

Fig. 6. Profil type de distribution granulométrique sur la poudre d'un tourteau d'aléa-protéagineux (colza; tournesol ou soja) (aire spécifique exprimée par rapport à la masse : $1741 \mathrm{~cm}^{2} / \mathrm{g}$ ).

\section{Profil de densité granulométrique des poudres}

Un profil type de distribution granulométrique mesuré sur les fines obtenues par classification granulométrique est représenté Figure 6.

Le diamètre médian des fines obtenu (D50) est de l'ordre de $30 \mu \mathrm{m}$.

\section{Identification et mesure de la taille des protéines}

Les gels d'électrophorèses SDS-PAGE en conditions réductrices des différents produits (poudres colza et soja et surnageants d'extraction de ces poudres) sont présentés Figures 7 et 8 . Les fractions insolubles obtenues après centrifugation n'ont pas été analysées, car elles restent très peu solubles dans le tampon choisi.

En milieu réducteur, les polypeptides $\alpha$ et $\beta$ sont identifiés. Dans le tourteau broyé de colza, les deux bandes de napines (i.e. albumines) sont mal résolues, tandis qu'elles sont bien identifiées dans les surnageants. Le profil électrophorétique observé pour la poudre ne représente pas intrinsèquement 
Tableau 2. Composition en protéines pour les tourteaux de soja et de colza.

\begin{tabular}{|c|c|c|}
\hline $\begin{array}{l}\text { Soja } \\
\text { Protéines } 2 \mathrm{~s} \text { ( } \alpha \text { conglycinine) } \\
\text { Protéines } 7 \mathrm{~S} \text { ( } \beta \text { conglycinine) } 35 \% \text { des } \\
\text { protéines }\end{array}$ & $\begin{array}{l}\text { Etat natif } \\
22 \mathrm{kDa} \\
150-200 \mathrm{kDa}\end{array}$ & $\begin{array}{l}\text { Etat dénaturé } \\
3 \text { sous unités acide } \\
\text { a } 63 \mathrm{kDa} \\
a^{\prime} 67 \mathrm{kDa} \\
\beta \quad 47 \mathrm{kDa}\end{array}$ \\
\hline $\begin{array}{lllllll}\begin{array}{l}\text { Protéines } \\
\text { protéines }\end{array} & 11 & \mathrm{~S} & \text { (glycinine) } & 40 & \% & \text { des } \\
& & & & & & \\
\end{array}$ & $300-380 \mathrm{kDa}$ & $\begin{array}{l}3 \text { sous unités } A \text { acide au vois inage } \\
\text { de } 40 \mathrm{kDa} \\
3 \text { sous unités B basique au } \\
\text { vois in } 9 g \text { e de } 20 \mathrm{kDa}\end{array}$ \\
\hline Polymère de glycinine $15 \mathrm{~s}$ & & \\
\hline Colza & & \\
\hline Globuline $11 \mathrm{~S}$ (Crucifér ines) & $300-350 \mathrm{k} \mathrm{Da}$ & $\begin{array}{l}\text { a } 25-35 \mathrm{kDa} \\
\beta \text {. } 23-25 \mathrm{Kka}\end{array}$ \\
\hline Albumines $2 \mathrm{~S}$ (Napine) & $12,5-14,5 \mathrm{kDa}$ & $\begin{array}{l}\text { a } 4-4.5 \mathrm{kDa} \\
\beta 9-10 \mathrm{kDa}\end{array}$ \\
\hline
\end{tabular}

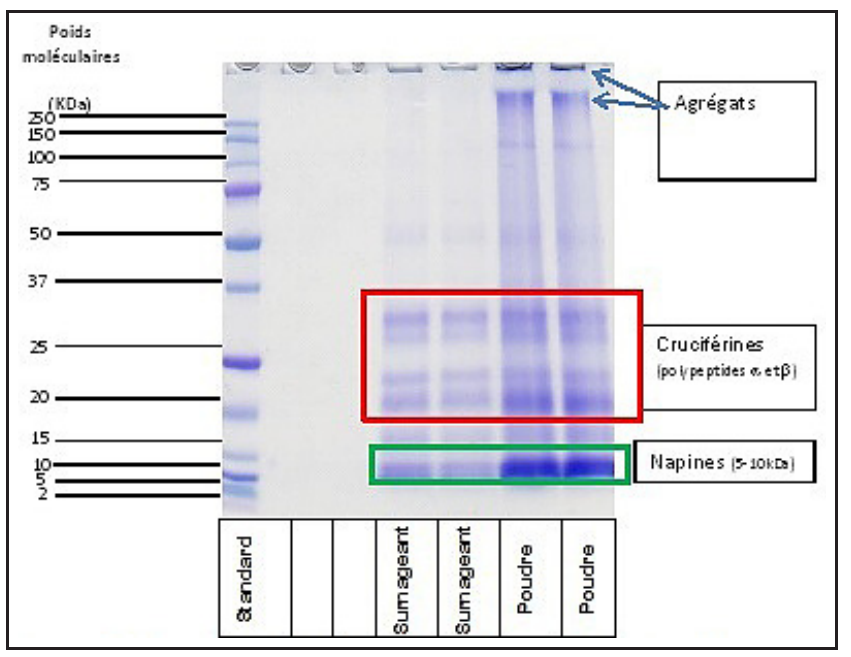

Fig. 7. Profil électrophorétique de l'extrait aqueux (2) et de la poudre de tourteau de colza en condition réductrice.

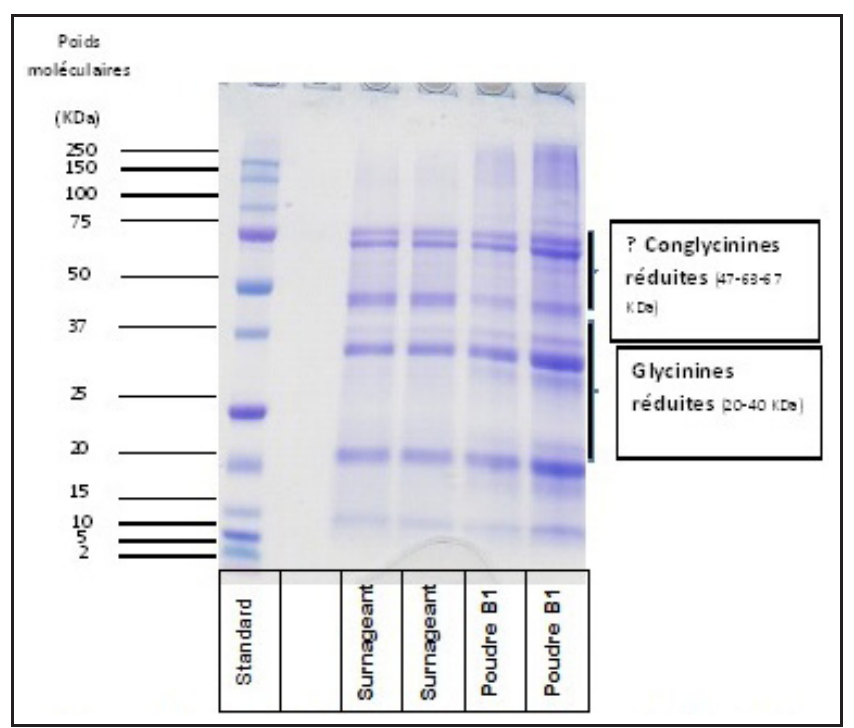

Fig. 8. Profil électrophorétique de l'extrait aqueux (2) et de la poudre de tourteau de soja en condition réductrice. l'ensemble des protéines de la poudre, mais seulement les protéines extractibles par le tampon d'échantillon.

Les valeurs des masses molaires détectées sont les suivantes :

- une bande entre 5 et $10 \mathrm{kDa}$ qui peut correspondre à un mélange de petites et grandes sous unités de napines dissociées par l'agent réducteur mais non séparées. Afin d'améliorer leur séparation, des électrophorèses dans ces conditions de gels plus réticulé permettraient de compléter ce travail.

- une bande à $15 \mathrm{kDa}$ (qui correspond aux sous unités de napines restées associées),

- un groupe de bandes autour de $20 \mathrm{kDa}$ qui correspondent à différentes sous unités béta de cruciférines (i.e. globulines) avec possiblement des oléosines,

- un groupe de bandes autour de $25 \mathrm{kDa}$ représentant les sous unités alpha des cruciférines,

- une bande peu intense à $50 \mathrm{kDa}$ qui représente une association de sous unités de cruciférines

Les polypeptides A et B de la glycinine sont identifiés. Dans le tourteau broyé de soja, des polymères (hauts poids moléculaires) et des bandes de polypeptides de glycinine plus nombreuses (agrégats insolubles) sont identifiés.

Ces photos de gels sont suivies par un tableau récapitulatif des tailles des molécules que nous identifions dans les différentes fractions ( $c f$. Tab. 2).

\section{Propriétés thermodynamiques}

Les propriétés thermodynamiques des différentes fractions ont été mesurées par microcalorimétrie différentielle ( $\mu$ DSC). Certains phénomènes sont endothermiques (dénaturation) et d'autres exothermique. Les résultats sont décrits dans le Tableau 3. Tous les thermogrammes obtenus sur les différents échantillons analysés ont été portés en annexe.

Pour les deux types d'échantillons, les thermogrammes montrent un effet endothermique lié à la dénaturation des protéines. L'intégration des pics de dénaturation permet de déterminer les chaleurs associées. La chaleur de dénaturation de la 
Tableau 3. Propriétés thermodynamiques des tourteaux et de leurs fractions.

\begin{tabular}{|c|c|c|c|c|c|}
\hline \multicolumn{2}{|l|}{$\begin{array}{l}\text { Produit } \\
\text { Tourteau déshuilé }\end{array}$} & \multirow{2}{*}{\begin{tabular}{|l|} 
Nature \\
Colza \\
Soja \\
Colza
\end{tabular}} & $\begin{array}{l}\text { Dénaturation } \\
\text { Ton set }\left({ }^{\circ} \mathrm{C}\right)\end{array}$ & $T \max \left({ }^{\circ} \mathrm{C}\right)$ & Chaleur $(\mathrm{J} / \mathrm{g})$ \\
\hline \multirow{3}{*}{$\begin{array}{l}\text { Fractionnement } \\
\text { des fines dans } \\
\text { l'eau - Etape } 2\end{array}$} & $\begin{array}{l}\text { Soluble } \\
\text { Insoluble }\end{array}$ & & $\begin{array}{l}76,0 \\
77,5\end{array}$ & $\begin{array}{l}82,1 \\
81,2\end{array}$ & $\begin{array}{l}0,09 \\
0,14\end{array}$ \\
\hline & Soluble & Soja & 89,9 & 94,9 & 0,19 \\
\hline & Insoluble & & 92,0 & 92,0 & 1,24 \\
\hline
\end{tabular}

Tableau 4. Propriétés fonctionnelles des fractions solubles et insolubles issues des fractions fines de tourteau de soja et de colza. Pour rappel, la tension de surface eaulair est de $72 \mathrm{mNlm}$ à $20^{\circ} \mathrm{C}$ et la tension interraciale huileleau est $20 \mathrm{mN} / \mathrm{m}$.

\begin{tabular}{|c|c|c|c|c|c|c|c|c|}
\hline \multicolumn{2}{|c|}{ Propriétés fonctionnelles } & \multicolumn{2}{|c|}{ Fraction soluble } & \multicolumn{2}{|c|}{ Fraction insoluble } & \multicolumn{3}{|c|}{ Protéines de référence } \\
\hline Caractéristique & $\begin{array}{l}\text { C } \text { protine dans } \\
\text { reau }\left(\%{ }^{\mathrm{plp}}\right)\end{array}$ & Colza & Soja & Colza & Soja & $\begin{array}{l}\text { Protéine } \\
\text { sérique laitière }\end{array}$ & $\begin{array}{l}\text { Caséinate } \\
\text { de sodium }\end{array}$ & $\begin{array}{l}\text { Blanc } \\
\text { d'œuf }\end{array}$ \\
\hline$V_{\text {mousee a 30s }}(\mathrm{mL})$ & 0,1 & 63 & 46 & 16 & 16 & & & 110 \\
\hline Geavar $(\mathrm{mN} / \mathrm{m})$ & 0.01 & 44 & 47 & 44 & 49 & & & \\
\hline Qezunue de toumesol $(\mathrm{m} / \mathrm{N} / \mathrm{m})$ & 0,1 & 9 & 18 & 22 & 22 & & & \\
\hline D50emus un nule dans eav $25.75(\mu \mathrm{m})$ & 0,75 & 28 & 20 & 60 & 68 & & $\sim 4$ & \\
\hline $\mathrm{h}(\mathrm{mPa} . \mathrm{s})$ & 15 & 2900 & 40 & & & & & \\
\hline $\mathrm{G}^{\prime} \max (\mathrm{Pa})$ & 15 & $<20$ & $<20$ & & & $\begin{array}{c}5000-8000(a ̀ \\
\left.90^{\circ} \mathrm{C}\right)\end{array}$ & & \\
\hline
\end{tabular}

fraction soluble de soja est significativement plus importante que celle mesurée pour le colza.

Pour les fractions insolubles, les températures de début de dénaturation sont décalées vers des valeurs supérieures à celles obtenues pour les fractions solubles. Le changement d'environnement physico-chimique mais aussi probablement l'obtention d'agrégats plus thermostables expliquerait ce décalage.

Le profil obtenu pour le colza donne un signal très faible, peu interprétable, signifiant que les protéines sont très dénaturées. Inversement, le signal est particulièrement net pour la fraction insoluble de soja.

Les pics exothermiques observés sur les thermogrammes pour les poudres et les fractions insolubles pourraient être dus à une dégradation de l'échantillon (e.g. carbonisation). La bonne hydratation des fractions solubles encapsulées sous pression corroborerait cette explication.

\subsubsection{Propriétés fonctionnelles apportées par les tourteaux de colza, tournesol et soja}

Les mesures ont été réalisées sur fractions solubles ou insolubles contenant des protéines et d'autres composés. Le Tableau 4 intègre ces résultats.

\section{Pression interfaciale air/eau et pouvoir moussant}

Les fractions solubles de colza et soja ont une tension de surface et un pouvoir moussant du même ordre de grandeur. Cette dernière caractéristique est environ deux fois plus faible que celle obtenue avec l'albumine de blanc d'œuf. Comparativement, les fractions insolubles moussent très peu, comme attendu.

\section{Pression interfaciale et pouvoir émulsifiant huile/eau \\ - Fractions solubles}

Les mesures de diamètres médians des émulsions d'huile dans l'eau en présence des fractions solubles des tourteaux ou bien des protéines de référence, réalisées à l'instant initial, ne semblent pas affectées par l'ajout de SDS. Le diamètre médian des émulsions ainsi obtenues est supérieur à celui obtenu avec du caséinate de sodium. L'aptitude de ces protéines de colza et soja à s'adsorber à l'interface est donc plus faible que celle du caséinate. Une étude de cinétique de viellissement des émulsions pourrait permettre de mettre en évidence les propriétés remarquables de stabilisation des émulsions par ces fractions solubles.

Par ailleurs, l'abaissement de la tension interfaciale eau/huile observé lors de l'addition de ces fractions solubles traduit la présence de protéines venant s'adsorber à l'interface eau/huile et capables de limiter les phénomènes de coalescence.

\section{- Fractions insolubles}

Comparativement, les fractions insolubles du soja et du colza présentent une tension interfaciale de l'ordre de $22 \mathrm{mN} / \mathrm{m}$, très proche de celle obtenue sans émulsifiant (environ de $20 \mathrm{mN} / \mathrm{m}$ ). Les protéines contenues dans ces fractions, sous forme insoluble, sont incapables de s'adsorber et de former une couche interfaciale. Elles présentent aussi un très faible pouvoir émulsifiant comme l'atteste la taille élevée des gouttelettes d'huile dans l'émulsion $\left(D_{50} \sim 60 \mu \mathrm{m}\right)$.

\section{Comportement rhéologique}

Les fractions solubles de colza et de soja présentent un comportement pseudo-plastique. Les fractions de colza apportent plus de viscosité que celles de soja. 


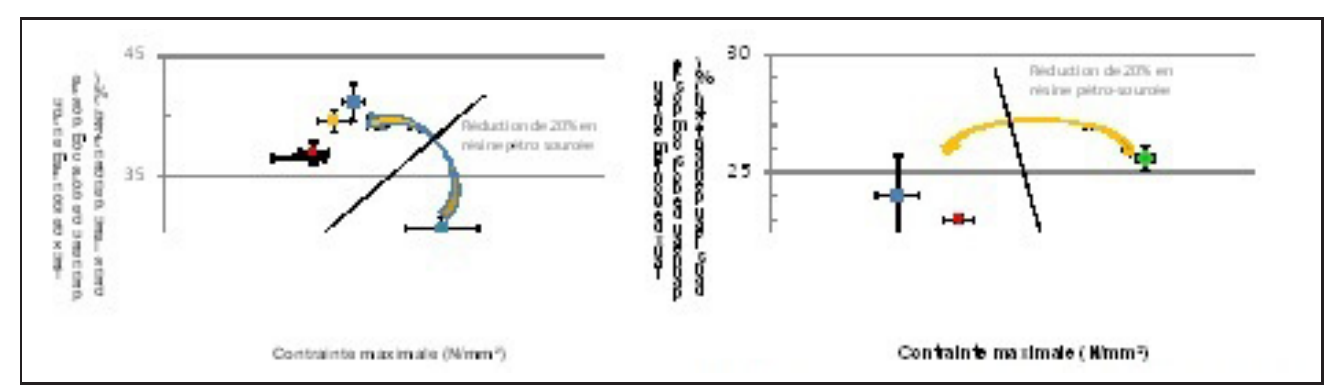

Fig. 9. Taux de gonflement à l'eau et propriétés mécaniques des panneaux de bois composite obtenus en additivant ou non les formulations adhésives de tourteau broyé de colza, de tournesol ou de soja. (a) Références : $7 \%$ UF (vert) ; 5,6 \% UF (rouge). Autres : 5,6 \% UF; $11 \%$ tourteau broyé de colza (bleu), tournesol (jaune) ou soja (noir) en pip par rapport à l'UF. (b) Références : $3 \%$ pMDI (vert) ; 2,4 \% pMDI (rouge) ; 2,4 \% pMDI ; $29 \%$ tourteau broyé de colza en pip par rapport au pMDI ; $10 \%$ uréel(urée + pMDI) (bleu).

Les fractions solubles des tourteaux de colza et soja obtenues par lyophilisation et dispersées dans l'eau à une concentration en protéines de $15 \%$, ne gélifient pas contrairement à certaines données de la littérature. Cela peut être dû à différents phénomènes :

- au cisaillement continu dans le rhéomètre au cours de la rampe de température (chauffage-refroidissement) qui peut casser le réseau protéique et empêcher la formation du gel ;

- au procédé d'obtention qui peut modifier la structure des protéines, mais surtout;

- à la présence d'autres constituants majeurs, présents dans ces fractions, qui peuvent perturber la formation du réseau protéique.

\subsubsection{Performances applicatives apportées par les tourteaux de colza, tournesol et soja}

Dans la présente étude, un remplacement seulement partiel des résines pétro-sourcées (pMDI ou UF) par du tourteau broyé est évalué dans le but d'identifier des synergies éventuelles de propriétés.

Dans le cas de l'UF (11\% de remplacement en p/p), le travail à iso-viscosité de formulation adhésive engendre une réduction de l'extrait sec de la formulation de 12 à $14 \%$ avec l'addition de tourteau broyé, et ce quelle que soit la nature du tourteau. Dans le cas du pMDI (29\% de remplacement en $\mathrm{p} / \mathrm{p}$ ), il engendre une réduction de l'extrait sec de la formulation adhésive de $54 \%$ avec l'addition de tourteau broyé de colza face à $59 \%$ avec l'addition de tourteau broyé de soja et cela pour atteindre une viscosité équivalente de la formulation adhésive sans ajout de tourteau broyé. Dans ce cas, l'extrait sec est plus fortement réduit en présence de tourteau broyé de soja qu'en présence de tourteau broyé de colza. Cette observation peut s'expliquer de la manière suivante :

- Les protéines de soja sont plus facilement extractibles (moins denaturées) que celles du colza, cela induisant une augmentation de viscosité de la formulation adhésive.

- Le soja comprend la $11 \mathrm{~S}$ et la 7S, deux protéines gélifiantes, contrairement au colza qui ne contient que la 1112S (cruciférine). L'autre protéine majeure du colza, la napine $(2 \mathrm{~S})$, a peu d'incidence sur la viscosité.

Les viscosités mesurées sur les formulations adhésives base UF et pMDI sont respectivement de 120 à $135 \mathrm{~s}$ et 190 à $240 \mathrm{~s}$.
Le temps de gel des formulations adhésives références base UF et pMDI sont respectivement de $480 \mathrm{~s}$ et $500 \mathrm{~s}$. Les temps de gel sont équivalents voir réduits en présence de tourteau broyé. Ils prennent respectivement les valeurs suivantes :

- pour les formulations base UF : $440 \mathrm{~s}$ à $480 \mathrm{~s}$ pour les tourteaux broyés de colza et de soja, et ce pour le remplacement de $11 \%$ de résine par du tourteau broyé;

- pour les formulations base pMDI : 200 s à 320 s pour les tourteaux broyés de colza et de soja, et ce pour le remplacement de $29 \%$ de résine par du tourteau broyé.

La tendance observée à la diminution du temps de gel peut être liée à la conjugaison de deux phénomènes :

- d'une part, dans le cas du pMDI, à la dilution de la formulation adhésive en présence de tourteau broyé (i.e. gélification prématurée de la formulation);

- d'autre-part, dans le cas de l'UF, à l'acidification de la formulation adhésive par l'ajout de tourteau broyé (i.e. accélération du durcissement de la résine).

Les propriétés de résistance mécanique et à l'eau sont schématisées Figure 9 pour deux types de résines.

Dans le cas du pMDI, si nous prenons comme référence celle réalisée à la même concentration en résine (symbole de couleur rouge), l'addition de farine de tourteau de colza ne joue pas significativement sur la propriété de résistance à l'eau des panneaux de bois composite. En revanche, une perte de résistance mécanique est à enregistrer.

Comparativement, dans le cas de l'UF, la résistance mécanique du panneau de bois composite est sensiblement améliorée avec l'incorporation de tourteau de colza ou de tournesol, mais reste inchangée avec l'incorporation de tourteau de soja. Une perte de résistance à l' eau est toutefois observée avec l'incorporation de tourteau de colza ou de tournesol, tandis qu' aucun changement n'est visible avec l'incorporation de tourteau de soja.

Par ailleurs, si le tourteau broyé est rajouté en substitution partielle de la résine pétro-sourcée (20\%), la résistance mécanique des panneaux de bois est sensiblement diminuée quel que soit le type de résine (UF ou pMDI).

En conclusion de cette section dédiée à l'application panneau de bois composite, l'addition de tourteau broyé dans les formulations adhésives joue un rôle important sur le comportement rhéologique de la formulation et sur le temps de gel, 
mais affecte dans une moindre mesure les propriétés de résistances mécanique et à l'eau des panneaux de bois composite et ce à iso-teneur en résine pétro-sourcée. La dilution de la formulation adhésive (forte dans le cas du pMDI à modérée dans le cas de l'UF) ainsi que le temps de contact de la formulation adhésive avec les copeaux de bois avant pressage relativement long au stade laboratoire (i.e. comparativement à l'échelle industrielle) pourraient expliquer ce résultat. Nos données préliminaires seront très utiles pour concevoir de nouvelles études qui amèneront à la production industrielle de nouveaux panneaux de bois.

\section{Conclusions et perspectives}

Une cartographie de l'activité inventive nous a ainsi permis de montrer que depuis une vingtaine d'années, l'intérêt de la recherche d'alternatives bio-sourcées aux produits d'origine fossile n'a de cesse de croître pour faire face à la pression réglementaire dans les secteurs des panneaux de bois composite et des mousses polyuréthane. Plus récemment, les matériaux protéiques ont été particulièrement étudiés dans ces domaines et leurs propriétés techno-fonctionnelles originales en font des ressources renouvelables de choix.

Concernant les propriétés moussantes, émulsifiantes, ou encore gélifiantes, les différents tests ont révélé que les fractions solubles extraites des tourteaux broyés ont, en fonction du type d'oléo-protéagineux, des performances variables qui, à ce stade, ne permettent pas toutefois d'égaler celles obtenues avec des protéines animales. Des développements et innovations sont nécessaires pour améliorer le procédé d'extraction et permettre notamment une amélioration des rendements et de la concentration des protéines dans l'extrait.

Sur la base de l'utilisation de tourteaux de colza, tournesol ou soja broyé ou encore de leurs extraits dans l'eau, les résultats ont montré des performances encourageantes en terme de propriétés applicatives. La préparation d'adhésifs plus verts a ainsi été réalisée avec succès.

Dans le domaine des adhésifs pour panneau de bois composite, les formulations adhésives additionnées de tourteaux broyés ont montré des propriétés rhéologiques intéressantes. Les propriétés de résistance mécanique et à l'eau mériteraient d'être évaluées à une échelle plus transposable à ce qui est réalisé en Industrie.

Ainsi, il ressort de cette étude que :

- L'apport de tourteau d'oléoprotéagineux (colza et tournesol) est possible dans des formulations de colles.

- Le rôle de la fraction protéique sur les propriétés applicatives des nouveaux matériaux ne semble pas avéré en terme de réaction primaire.

- Ces résultats sont toutefois encourageants et mériteraient de plus amples études notamment en terme de propriétés rhéologiques. Le tourteau de colza pourrait s'avérer d'intérêt comme additif rhéologique permettant une meilleure utilisation des résines pétro-sourcées utilisées dans les matériaux notamment les adhésifs pour panneaux de bois composites

La variabilité de composition et de propriétés physicochimiques d'un tourteau selon son procédé d'obtention peut affecter la taille des particules de la farine obtenue par broyage, et par extension les propriétés d'application. Des travaux ont été engagés sur l'aptitude au broyage des tourteaux de colza en fonction du procédé de trituration mais aussi sur la composition chimique plus fine des différentes fractions granulométriques de la farine. Ils seront complétés par l'étude des conditions d'extraction des bio-polymères en fonction de diverses conditions physico-chimiques.

\section{Références}

Amaral-Labat GA, Pizzi A, Goncalves AR, et al. 2008. Environmentfriendly soy flour-based resins without formaldehyde. J. App. Polym. Sci. 108: 624-632.

Cheng HN, Dowd MK, He Z. 2013. Investigation of modified cottonseed protein adhesives for wood composites. Ind. Crops Prod. 46: 399-403.

Cunningham RL, Carr ME, Bagley EB. 1992. Preparation and properties of rigid polyurethane foams containing modified corn starch. J. Appl. Polym. Sci. 44: 1477-1483.

He Z, Chapital DC, Cheng HN, Dowd MK. 2014. Comparison of adhesive properties of water- and phosphate buffer-washed cottonseed meals with cottonseed protein isolate on maple and poplar veneer. Int J. Adhes. Adhesives 102-106.

Hettiarachchy NS, Kalapathy U, Myers DJ. 1995. Alkali-modified soy protein with improved adhesive and hydrophobic properties. J. Am. Oil Chem. Soc. 72: 1461-1464.

Khosravi S, Khabbaz F, Nordqvist P, Johansson M. 2010. ProteinBased Adhesives For Particleboards. Ind. Crops Prod. 32: 275283.

Lei H, Pizzi A, Navarrete P, et al. 2010. Gluten protein adhesives for wood panels. J. Adhes. Sci. Technol. 24: 1583-1596.

Li X, Pizzi A, Cangemi M, et al. 2012. Insulation rigid and elastic foams based on albumin. Ind. Crops Prod. 37: 149-154.

Lin Y, Hsieh F, Huff HE. 1997. Water-blown flexible polyurethane foam extended with biomass materials. J. Appl. Polym. Sci. 65: 695-703.

Marutsky, R. 1989. Release of formaldehyde by wood products. Wood adhesives - Chemistry and Technology, Marcel Dekker, Inc., pp. 307-387.

Nordqvist P, Khabbaz F, Malmstrom E. 2010. Comparing bond strength and water resistance of alkali-modified soy protein isolate and wheat gluten adhesives. Int J. Adhes. Adhesives 30: 72 79.

Wang DH, Sun XS. 2002. Low density particleboard from wheat straw and corn pith. Ind. Crops Prod. 15 : 43-50.

Wool RP, Sun XS. 2005. Bio-based polymers and composites. Boston: Elsevier Inc., pp. 292-236.

Zhong Z, Sun XS, Wang D, Ratto JA. 2003. Wet strength and water resistance of modified soy protein adhesives and effects of drying treatment. J. Polym. Environ. 11 : 137-144.

\footnotetext{
Cite this article as: Aurélie Morel, Nathalie Mantrand, Saliha Belaid, Michel Lopez, Denis Chereau, Camille Demaille, Stéphane Pailler, Francis Valter, Olivier Galet, Jacques Gueguen, Romain Kapel, Antonio Pizzi, Fabrice Garrigue. Le marché potentiel des tourteaux broyés, leurs propriétés fonctionnelles et applications. OCL 2016, 23(4) D408.
} 